\title{
ERRATA
}

\section{Analytical Approximations of Sensitivities of Steady State Predictions to Errors in Parameter Estimation ${ }^{1}$}

\section{Igor Gonda $\mathbf{a}^{2,3}$}

Eqs. 10-12 should read

$$
\begin{aligned}
& S\left(C_{2}\right)=\left|\left[1+\frac{C_{1}\left(e^{\lambda_{2} \tau}-1\right)}{C_{2}\left(e^{\lambda_{1} \tau}-1\right)}\right]^{-1}\right| \\
& S\left(\lambda_{1}\right)=\left|-\lambda_{1} \tau\left[\left(1-e^{-\lambda_{1} \tau}\right)\left(1+\frac{C_{2}\left(e^{\lambda_{1} \tau}-1\right)}{C_{1}\left(e^{\lambda_{2} \tau}-1\right)}\right)\right]^{-1}\right| \\
& S\left(\lambda_{2}\right)=\left|-\lambda_{2} \tau\left[\left(1-e^{-\lambda_{2} \tau}\right)\left(1+\frac{C_{1}\left(e^{\lambda_{2} \tau}-1\right)}{C_{2}\left(e^{\lambda_{1} \tau}-1\right)}\right)\right]^{-1}\right|
\end{aligned}
$$

Inequalities (24) should read

$$
0 \leq S\left(C_{i}\right) \leq 1 \quad i=1,2
$$

The word "Then" before eq. (29) should be omitted.

The sentence before eq. 43 should read: "The limiting behavior of Eqs. (38)-(41) is ..."

Eq. 51 should be inserted after eq. 50 :

$$
S\left(k_{10}\right)=\left|\frac{k_{10}}{k_{01}-k_{10}}-\frac{k_{10} t e^{-k_{10} t}}{e^{-k_{10} t}-e^{-k_{01} t}}\right|
$$

The note before eq. (A.5) should be "... c.f. Eqs. (25) and (A2)..." Reference 11 was withdrawn from the cited abstracts because the authors were unable to attend the symposium. However, a copy of an extendled abstract is available on request from I.G.

\footnotetext{
${ }^{1}$ Journal of Pharmacokinetics and Biopharmaceutics, 10: 559-574 (1982).

${ }^{2}$ Department of Pharmacy, University of Aston in Birmingham, Gosta Green, Birmingham, B4 7ET, U.K.

${ }^{3}$ Present address: Department of Pharmacy, University of Sydney, Sydney, NSW 2006, Australia.
} 